\title{
Editorial
}

\section{Healing Preferences among Tribal Patients with Mental Illness in India}

\author{
Ram Lakhan ${ }^{1}$ \\ ${ }^{1}$ Department of Health and Human Performance, Berea College, \\ Berea, Kentucky, United States
}

J Neurosci Rural Pract:2020;11:366-366

I have read the letter to the editor "Healing Preferences among Tribal Patients with Mental Illness in India" with great interest. ${ }^{1}$ Healing preferences for mental illness among tribal people is a poorly researched subject. Authors have found that $36 \%$ of tribal people approach traditional healers, $28 \%$ do not consult any type of healers or professionals including traditional healers and medical professionals, and $64 \%$ do not consult medical professionals on the onset of mental illness. The research provides two directional messages, indicating that a large percentage of tribal people prefer traditional healing over treatment from medical professionals. These findings are very crucial to understanding the pathways of care for mental illness among tribal people.

It would be of great significance to science if the researchers had collected information about their entire journey, from the onset of the problem to the decision to reach medical professionals for the healing of their mental health issues. The reasons for preferring traditional healing are widely understood in mental health. ${ }^{2}$ Studies have reported that up to $88 \%$ of people with mental illness in low- and middleincome countries consider traditional healing as their first point of care. A large percentage also consider traditional healing in combination with Western medical care as their first point of care. ${ }^{3}$ It is, however, novel information that a larger percentage of tribal people do not prefer to approach medical professionals. Preferences toward traditional healing could be due to multiple sociodemographic factors experienced by rural Indians, including a lack of awareness, lack of resources, physical inaccessibility, unavailability of services, biased approaches of medical professionals, inherited perception toward mental illness, and a lack of successful examples of medical care in communities. ${ }^{4,5}$

However, the question of what the main reasons responsible for not preferring medical professionals for mental healthcare in tribal India are remains unanswered. Recent studies have reported that a majority of people believe in traditional healing in India and think that people should approach traditional healers first. ${ }^{6,7} \mathrm{~A}$ widespread, favorable perception toward traditional healing for mental illness in India may likely be a factor that builds opposing attitudes toward Western medical care for treating mental illness among tribal people. People doubt these healers as they do not provide clear explanations for the problem and its prognosis. ${ }^{7}$ Researchers should look deeper into understanding the perceptual and attitudinal factors toward pathways of mental healthcare among tribal people.

\section{Conflict of Interest}

None declared.

\section{References}

1 Subudhi C, Biswal R, Meenakshi JR. Healing Preferences among Tribal Patient with Mental Illness in India.Journal of Neurosciences in Rural Practice. 2020; J Neurosci Rural Pract 2020;11:361-362

2 Thirthalli J, Zhou L, Kumar K, et al. Traditional, complementary, and alternative medicine approaches to mental health care and psychological wellbeing in India and China. Lancet Psychiatry 2016;3(7):660-672

3 Ali TM, Gul S. Community mental health services in Pakistan: review study from Muslim world, 2000-2015. Psychol Community Health 2018;7(1):57-71

4 Kumar MM, Pathak VK, Ruikar M. Tribal population in India: a public health challenge and road to future. J Family Med Prim Care 2020;9(2):508-512

5 Shidhaye R, Patel V. Association of socio-economic, gender and health factors with common mental disorders in women: a population-based study of 5703 married rural women in India. Int J Epidemiol 2010;39(6):1510-1521

6 Ningsangrenla L, Rao PSS. Traditional healing practices and perspectives of mental health in Nagaland. Journal of North East India Studies 2019;9(2):33-56

7 Schoonover J, Lipkin S, Javid M, et al. Perceptions of traditional healing for mental illness in rural Gujarat. Ann Glob Health 2014;80(2):96-102
Address for correspondence Ram Lakhan, DrPH, Department of Health and Human Performance, Berea College, Berea, KY 40404, United States

(e-mail: ramlakhan15@gmail.com).
DOI https://doi.org/ 10.1055/s-0040-1713574 ISSN 0976-3147.
C2020 Association for Helping

Neurosurgical Sick People
License terms

()(1) $\odot \circledast$ 